\title{
Estimation of Salivary and Serum Calcium Levels in Smokers and Nonsmokers with Chronic Periodontitis
}

\author{
${ }^{1}$ Suresh K Kasagani, ${ }^{2}$ Aditya Rao, ${ }^{3}$ Suma Rajan, ${ }^{4}$ Ghousia Fatima, ${ }^{5}$ Roopali Tapashetti
}

\begin{abstract}
Studies in the past investigated the role played by minerals in the etiology and/or progression of periodontal disease for more than four decades. Various host defense factors are present in the saliva. It also influences calculus formation and thus periodontal disease. Recent studies have shown a significant relationship between dietary calcium, serum calcium, and periodontal disease. Smoking marks a major risk factor for both periodontal disease and several systemic diseases. So, the aim of the present study is to estimate salivary and serum calcium levels in smokers and nonsmokers with chronic periodontitis.
\end{abstract}

Materials and methods: The study comprised 30 subjects, equally divided into three groups of clinically healthy periodontium, nonsmokers with chronic periodontitis, and smokers with chronic periodontitis. Clinical measurements, saliva, and blood samples were obtained. Biochemical analysis for the estimation of calcium was performed. Blood samples were collected through venipuncture method.

Results: Comparison of mean serum calcium between the three groups by analysis of variance showed highly statistically significant difference $(F=23.92, p=0.001)$.

Conclusion: Smokers with periodontitis exhibited reduced levels of calcium as compared with nonsmokers with periodontitis and the differences were statistically significant.

Keywords: Calcium, Chronic periodontitis, Smokers and nonsmokers.

How to cite this article: Kasagani SK, Rao A, Rajan S, Fatima G, Tapashetti R. Estimation of Salivary and Serum Calcium Levels in Smokers and Nonsmokers with Chronic Periodontitis. J Health Sci Res 2016;7(2):35-37.

Source of support: Nil

Conflict of interest: None

\section{INTRODUCTION}

Calcium is the most abundant minerals in humans. About $99 \%$ of the total calcium in the human body exists in the bones and teeth, providing a structural function; the

${ }^{1}$ Professor and Head, ${ }^{2}$ Senior Lecturer, ${ }^{3}$ Postgraduate Student ${ }^{4}$ Professor, ${ }^{5}$ Reader

${ }^{1-5}$ Department of Periodontics, Al-Badar Dental College and Hospital, Gulbarga, Karnataka, India

Corresponding Author: Suma Rajan, Postgraduate Student Department of Periodontics, Al-Badar Dental College and Hospital, Gulbarga, Karnataka, India, Phone: +918971017156 e-mail: sumarajan72@gmail.com remaining $1 \%$ is found in tissues and fluids and is crucial for the maintenance of cell metabolism, nerve transmission, and muscle contraction.

Researchers have been exploring the role played by minerals in the etiology and/or progression of periodontal disease for more than four decades. Recent studies have shown a significant relationship between dietary calcium, serum calcium, and periodontal disease.

Confounding and effective modification are of increasing importance as periodontal research addresses putative associations between periodontal disease and systemic disease. This is especially pertinent when dealing with smoking, as smoking is a major risk factor for both periodontal disease and several systemic diseases. ${ }^{1}$ However, evidence from physiological and clinical studies regarding the mechanism by which calcium and magnesium are associated with periodontal disease, adjusted for smoking habits, is lacking. The purpose of the present study was to evaluate the independent association between serum and salivary calcium, taking smoking habits into consideration.

\section{MATERIALS AND METHODS}

The study comprised 30 subjects, equally divided into three groups of clinically healthy periodontium, nonsmokers with chronic periodontitis, and smokers with chronic periodontitis. Clinical measurements, saliva, and blood samples were obtained. The study was approved by Institutional Ethical Committee of Al-Badar Dental College and Hospital, Gulbarga, Karnataka, India. Written consent was taken from patients prior to commencement of the study.

\section{Inclusion Criteria}

Age above 18 years; systemically healthy patients; and patients with pockets more than $4 \mathrm{~mm}$.

\section{Exclusion Criteria}

Systemic diseases using medications affecting salivary secretions and calcium levels; pregnant and lactating women with severe immune deficiency.

\section{Determination of Salivary Calcium}

Calcium determination was carried out by BioMérieux (France) calcium kit using spectrophotometer end-point 
method and reading results by a spectrophotometer (CECIL 1021, England) at $650 \mathrm{~nm}$ wavelength. ${ }^{2}$ The principle is dependent on the reaction of Arsenazo III, which reacts with calcium in a slightly acidic medium to form bluepurple complex. The intensity of the color is proportional to calcium concentration. The measurement of optical density (OD) was carried out at $650 \mathrm{~nm}$ against the blank. The calculation was done according to the following equation:

$$
\begin{aligned}
& \frac{\mathrm{OD} \text { of sample }}{\mathrm{OD} \text { of standard }} \times \text { Standard concentration } \\
& =\text { Concentration of calcium in mmol/L }
\end{aligned}
$$

\section{Blood Collection}

An elastic band around subject's upper arm was wrapped to stop the flow of blood. It is easier to put a needle into the vein because the veins beneath the band appear larger. The needle site was cleaned with alcohol and the needle was punctured into the vein. More than one needle stick may be needed and a tube was attached to the needle to fill it with blood. The band was removed from the subject's arm when enough blood is collected. The normal values listed here, called a reference range, were just a guide. These ranges may vary from lab to lab. Normal blood calcium is 2.2 to $4.5 \mathrm{meq} / \mathrm{L}$.

\section{STATISTICAL ANALYSIS}

All the three group's salivary and serum calcium levels were reported as mean and standard deviation (SD) of $\mathrm{mg} / \mathrm{dL}$.

The statistical significance of differences in salivary and serum calcium levels between healthy smoking and nonsmoking groups were estimated by one-way analysis of variance (ANOVA) followed by Scheffe's multiple comparison tests.

A p-value of $<0.05$ was accepted as significance.

\section{RESULTS}

From Table 1, it is clear that the group 1 participants with clinically healthy periodontium had higher mean of $5.76 \pm 1.11$ of salivary calcium followed by group 2 nonsmokers with chronic periodontitis $(5.49 \pm 0.93)$, and group 3 smokers with chronic periodontitis $(4.52 \pm 0.64)$. Further comparison of mean salivary calcium between the three groups by ANOVA showed statistically significant difference $(\mathrm{F}=5.07, \mathrm{p}=0.014)$.

Table 1: Comparison of salivary calcium among different study groups by ANOVA

\begin{tabular}{lllllll}
\hline Salivary calcium & $n$ & Mean & $S D$ & Std. error & $F$ & Sig. \\
\hline Group I & 10 & 5.76 & \pm 1.11 & 0.354 & 5.05 & 0.014 \\
Group II & 10 & 5.49 & 0.93 & 0.294 & & \\
Group III & 10 & 4.52 & 0.64 & 0.202 & & \\
\hline
\end{tabular}

Table 2: Comparison of serum calcium among different study groups by ANOVA

\begin{tabular}{lllllll}
\hline Serum calcium & $n$ & Mean & SD & Std. error & $F$ & Sig. \\
\hline Group I & 10 & 11.22 & 0.74 & 0.236 & 23.92 & 0.001 \\
Group II & 10 & 9.18 & 0.70 & 0.222 & & \\
Group III & 10 & 10.32 & 0.51 & 0.161 & & \\
\hline
\end{tabular}

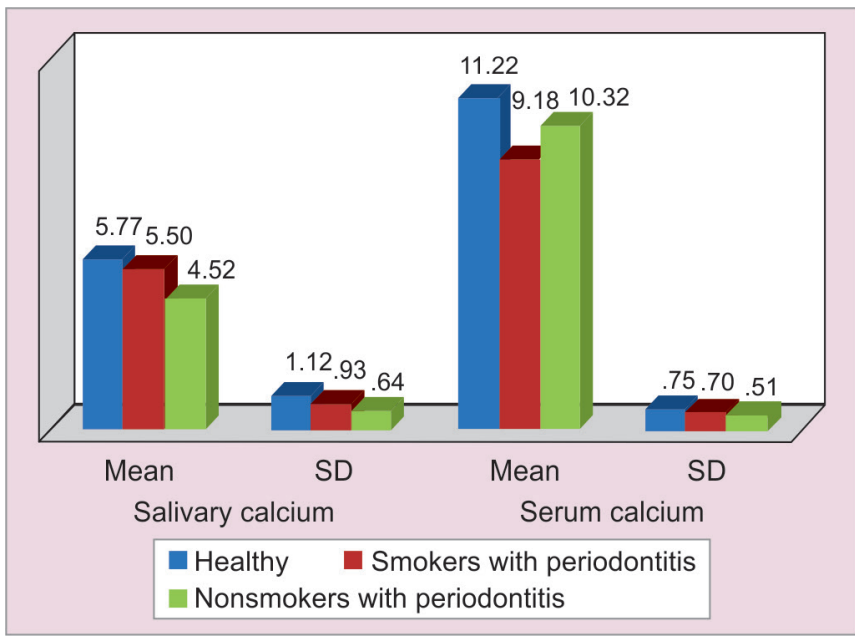

Graph 1: Mean and SD of serum and salivary calcium in different study groups

Similarly, group 1 study participants with clinically healthy periodontium had higher mean value $(11.22 \pm 0.74)$ of serum calcium followed by group 3 smokers with periodontitis (10.32 \pm 0.51$)$, and group 2 nonsmokers with chronic periodontitis $(9.18 \pm 0.70)$. Comparison of mean serum calcium between the three groups by ANOVA showed highly statistically significant difference $(\mathrm{F}=23.92$, $\mathrm{p}=0.001$ ), as shown in Table 2. Mean and SD have been depicted in Graph 1.

\section{DISCUSSION}

Salivary phosphorous and calcium have been associated with the deposition of tartar and formation of calculus over the teeth. Apparently, high level of salivary calcium is responsible for the resistance to dental decay. In comparison with other minerals, human body contains more calcium, as much as $1200 \mathrm{gm}$ in a $70 \mathrm{~kg}$ adult. The most skeletal calcium is deposited in the form of hydroxyapatite $\mathrm{Ca}_{10}\left(\mathrm{PO}_{4}\right)_{6}(\mathrm{OH})_{2}$. Salivary calcium is related to plasma levels and under resting condition it is about $3 \mathrm{mmol} / \mathrm{L}$.

Many previous reports indicated a significant association between smoking and periodontal disease. Nicotine derivatives are also known to be vasoconstrictive not only on peripheral vessels but also on coronary, placental, and gingival blood vessels. ${ }^{3}$ Tobacco use may reduce the functional activities of polymorphonuclear leucocytes including chemotaxis and phagocytosis. ${ }^{4}$

Likewise, smoking also has significant systemic effects on plasma IgG levels. ${ }^{5}$ Saliva is a major influencing 
factor for plaque initiation, maturation, and metabolism. The composition of saliva and its flow influence the formation of calculus and periodontal disease.

Plaque is composed of inorganic components, predominantly phosphorous and calcium with trace amounts of other minerals, such as potassium and sodium. Primarily the source of inorganic components of supragingival plaque is from saliva. As the mineral components increase, the plaque mass gets calcified, which results in the formation of calculus. ${ }^{6}$

Sewón et $\mathrm{al}^{7-12}$ with their series of studies have shown that oral mineralization potential of saliva plays an important role in periodontal health and disease. Mineralization-favoring factors are known to maintain the integrity of enamel surfaces, and intraoral mineralization capacity has been a matter of scientific interest for decades. ${ }^{13,14}$

In the present study, compared to nonsmokers lower content of Ca was observed in smokers in both serum and saliva. Except plaque index and gingival Index, there was no statistically significant difference in the mean levels of clinical parameters between the groups. These results are similar to the study conducted by Zuabi et $\mathrm{al}^{15}$ and in contradiction to those obtained by Erdemir and Erdemir. ${ }^{16}$ The differences could be attributed to the different techniques that were employed for biochemical analysis. ${ }^{17}$

\section{CONCLUSION}

Smokers with periodontitis exhibited reduced levels of calcium as compared with nonsmokers with periodontitis and the differences were statistically significant.

More studies including prospective trials are necessary to understand the exact nature of the relationship between periodontal disease and serum calcium, taking smoking habits into consideration.

\section{REFERENCES}

1. Hyman J. The importance of assessing confounding and effect modification in research involving periodontal disease and systemic disease. J Clin Periodontol 2006 Feb;33(2):102-103.

2. Hassan SA, Al-Sandook TA. Salivary calcium concentration in patients with high incidence of calculus formation. Al-Rafidain Dent J 2005;5(1):88-90.
3. Leow NM, Morel-Kopp MC, Woodward M, Chen Q, Tofler GH, Taylor BA. The relationship between cotinine and periodontal disease. Ann R Australas Coll Dent Surg 2006 Sep;18:51-52.

4. Persson L, Bergström J, Ito H, Gustafsson A. Tobacco smoking and neutrophil activity in patients with periodontal disease. J Periodontol 2001 Jan;72(1):90-95.

5. Fredriksson M, Bergström K, Asman B. IL-8 and TNF-alpha from peripheral neutrophils and acute-phase proteins in periodontitis: effect of cigarette smoking: a pilot study. J Clin Periodontol 2002 Feb;29(2):123-128.

6. Haake SK, Newman MG, Nisengard RJ, Sanz M. Periodontal microbiology. In:NewmanMG, TakeiHH,Carranza FA, editors. Carranza's clinical periodontology. Vol. 6. Philadelphia (PA): WB Saunders; 2002. p. 96-112.

7. Sewón L, Söderling E, Karjalainen S. Comparative study on mineralization-related intraoral parameters in periodontitisaffected and periodontitis-free adults. Scand J Dent Res 1990 Aug;98(4):305-312.

8. Sewón L, Mäkelä M. A study of the possible correlation of high salivary calcium levels with periodontal and dental conditions in young adults. Arch Oral Biol 1990;35 (Suppl):211S-212S.

9. Sewón LA, Parvinen TH, Sinisalo TV, Larmas MA, Alanen PJ. Dental status of adults with and without periodontitis. J Periodontol 1988 Sep;59(9):595-598.

10. Sewón L, Söderling E, Karjalainen S. A mineral-related feature of young plaque characteristic to periodontitisaffected adults. J Periodontol 1990 Jan;61(1):42-44.

11. Sewón LA, Karjalainen SM, Sainio M, Seppä O. Calcium and other salivary factors in periodontitis-affected subjects prior to treatment. J Clin Periodontol 1995 Apr;22(4):267-270.

12. Sewón LA, Karjalainen SM, Söderling E, Lapinleimu H, Simell O. Associations between salivary calcium and oral health. J Clin Periodontol 1998 Nov;25(11 Pt 1):915-919.

13. Robinson LJ, Blair HC, Barnett JB, Zaidi M, Huang CL. Regulation of bone turnover by calcium-regulated calcium channels. Ann NY Acad Sci 2010 Mar;1192:351-357.

14. Brown LF, Beck JD, Rozier RG. Incidence of attachment loss in community-dwelling older adults. J Periodontol 1994 Apr;65(4):316-323.

15. Zuabi O, Machtei EE, Ben Aryeh H, Ardekian L, Peled M, Laufer D. The effect of smoking and periodontal treatment on salivary composition in patients with established periodontitis. J Periodontol 1999 Oct;70(10):1240-1246.

16. Erdemir EO, Erdemir A. The detection of salivary minerals in smokers and non-smokers with chronic periodontitis by the inductively coupled plasma atomic emission spectrophotometry technique. J Periodontol 2006 Jun;77(6):990-995.

17. Edwards SL. Maintaining calcium balance: physiology and implications. Nurs Times 2005 May 10-16;101(19):58-61. 